\title{
A Novel Clutchless Multiple-Speed Transmission for Electric Axles
}

\author{
Aldo Sorniotti* and Thomas Holdstock \\ University of Surrey \\ Guildford \\ Surrey \\ GU2 7XH \\ United Kingdom \\ Email: a.sorniotti@surrey.ac.uk \\ Email: t.holdstock@surrey.ac.uk \\ *Corresponding author \\ Mike Everitt and Marco Fracchia \\ Vocis Driveline Controls \\ American Barns \\ Banbury Road \\ Lighthorne, Warwick \\ CV35 0AE \\ United Kingdom \\ Email: mike.everitt@ vocisdrivelinecontrols.com \\ Email: marco.fracchia@ vocisdrivelinecontrols.com \\ Fabio Viotto, Carlo Cavallino and Stefano Bertolotto \\ Oerlikon Graziano SpA \\ Via Cumiana 14 \\ 10098 Rivoli (Torino) \\ Italy \\ Email: fabio.viotto@oerlikon.com \\ Email: carlo.cavallino@oerlikon.com \\ Email: stefano.bertolotto@oerlikon.com
}

\begin{abstract}
Fully electric vehicles and range-extended electric vehicles can be characterised by a multitude of possible powertrain layouts, many of them currently under investigation and comparison. This contribution presents a novel clutchless seamless four-speed transmission system which can be concurrently driven by two electric motor drives, for use in fully electric vehicles or electric axles for through-the-road parallel hybrid electric vehicles. The transmission system allows the electric motors to work in their high efficiency region for a longer period during a typical driving schedule.
\end{abstract}


This paper describes the layout of the novel transmission system, the equations for modelling its dynamics and the criteria for the selection of the best gearshift maps for energy efficiency. Finally, an energy consumption and performance comparison between the novel drivetrain, a conventional single-speed electric drivetrain and a double-speed electric drivetrain is discussed in detail for two case study vehicles.

Keywords - Vehicle; electric drivetrain; clutchless; seamless; gearshift; efficiency

Biographical notes: Aldo Sorniotti has received an MSc degree in mechanical engineering in 2001 and a $\mathrm{PhD}$ in applied mechanics in 2005 at the Politecnico di Torino, Italy. He is Senior Lecturer in advanced vehicle engineering at the University of Surrey, UK. His research interests focus on vehicle dynamics control and mechanical transmissions for fully electric and hybrid electric vehicles. He has authored over 80 conference and journal papers.

Thomas Holdstock has received a BEng degree in aerospace engineering at the University of Surrey, UK, in 2007. After two years working in industry for a control systems company, he is currently studying for a $\mathrm{PhD}$ at the University of Surrey. His research focuses on the modelling and optimisation of state-of-the-art transmissions for electric vehicles, along with hardware-in-the-loop testing.

Mike Everitt has received an MBA, masters in business administration (1990). He is a co-founder and managing director of Vocis Ltd. and has responsibility for a wide range of transmission related design and development projects, he is the co-author of the 4-speed dual-motor electric drivetrain patent. He has been involved in significant transmission project delivery since 1996 including the Bugatti Veyron.

Marco Fracchia has received an MEng degree in mechanical and automotive engineering (2000). He is a Technical Specialist at Vocis Ltd. and has responsibility for a wide ranging scope of activities related to transmission software development. This includes generating new software for use in new and novel applications based on the core Vocis software.

Fabio Viotto has received an MSc degree in automotive engineering at the Politecnico di Torino, Italy, in 1998. He is Product Manager for electric vehicle and hybrid electric vehicle applications in the Automotive Product Development department at Oerlikon Graziano, Italy. His research focus includes design and testing of electric and hybrid electric vehicle 
drivetrains. He has actively contributed to the writing of several technical papers.

Carlo Cavallino has received an MSc degree in mechanical engineering at the Politecnico di Torino, Italy, in 2004. He is Project Development Engineer at Oerlikon Graziano (Italy). His professional and research interests include design and testing of dual clutch and automated manual transmission systems for automotive applications. He has actively contributed to the writing of several technical papers about the subject.

Stefano Bertolotto has received an MSc degree in automotive engineering at the Politecnico di Torino, Italy, in 2010. He is Design Engineer at Oerlikon Graziano, Italy, working on the development and testing of mechanical transmissions for electric and hybrid electric vehicles and has authored several technical papers about the subject.

\section{Introduction}

Electro-mobility is a prevalent area of research in the automotive sector today. One of the major challenges for vehicle manufacturers is the selection of the best possible fully electric vehicle drivetrain architecture for their specific application. The adoption of electric motor drives permits a higher level of vehicle layout flexibility than internal combustion engines, predominantly due to the reduced space requirement of the powertrain and ancillaries. The first modern fully electric vehicles developed by the leading car makers (Renault, 2012) are characterised by a two-wheel-drive layout with a centrally located electric motor drive, coupled to the wheels through a single-speed gearbox, a differential and half-shafts. The main driving factor for this architecture being initially adopted is cost, as a single electric motor drive coupled to a basic single-speed transmission represents the most cost-effective solution whilst not implying a significant performance limitation.

However, a large body of literature (for example, Knodel, 2009; Ren, Crolla and Morris, 2009; Sorniotti et al., 2011) has demonstrated that the adoption of multiple-speed transmissions could significantly benefit the energy efficiency and performance of fully electric vehicle drivetrains. For example, the results of a questionnaire (Rinderknecht and Meier, 2010) completed by the attendees of the CTI 2010 conference (a major conference for industrialists in the area of automotive transmissions) pointed out that multiple-speed mechanical transmissions are the expected future standard solution to improve fully electric vehicle efficiency.

The typical torque characteristic of an electric motor drive is comprised of a constant torque region followed by a constant power region. Due to the 
constant torque region having a limited speed range, a significant number of gearshifts are usually carried out in the constant power region. Gearshifts performed in the constant power region are disadvantageous in terms of the vehicle acceleration time and drivability (measured by the jerk of the vehicle), as the vehicle acceleration level remains the same before and after the gearshift, and any torque gap would represent a perceivable drawback of a multiple-speed transmission. As such, a transmission capable of providing seamless gearshifts is of great importance for a fully electric vehicle.

In this respect, (Rinderknecht, Meier and Fietzek, 2011) proposes a seamless transmission system concept based on the adoption of two electric motor drives, each of them can be connected to either one of two gear ratios, giving origin to nine states. The drivetrain can also be characterised by an internal combustion engine for battery recharging or to provide a tractive torque, if a friction clutch is implemented allowing the internal combustion engine to be connected to/disconnected from the system. (Rinderknecht, Meier and Fietzek, 2011) explains the basic layout of the system concept and provides some hints of the possible advantages over single-motor electric drivetrains, however it does not supply any analytical tool or experimental proof of the actual achievable benefit. For reasons of standardisation and cost-effectiveness, the authors of (Rinderknecht, Meier and Fietzek, 2011) suggest the adoption of the same electric machines and gear ratios on each primary shaft of the system, without any presentation of actual quantitative evaluation or design optimisation.

The authors of this contribution working with industrial companies have been involved in the implementation of a physical prototype of this novel transmission concept (Bologna, Everitt and Fracchia, 2011). This article, which describes a joint research activity between academia and industry, provides the mathematical equations and the analytical instruments required to evaluate the potential energy efficiency and performance benefits obtainable through this transmission concept. Also, the article will provide an insight into the possible automated model-based design methodologies for the selection of the optimal state and torque distribution maps. Finally, the system will be evaluated for two case study vehicle applications, characterised by very different data sets, and compared with single-speed and double-speed single-motor drivetrains.

\section{The Novel Transmission Concept}

Figure 1 is a schematic of the electric powertrain including the novel transmission, patented in (Bologna, Everitt and Fracchia, 2011). This is characterised by an 'odd' electric machine, which is connected to the 'odd' primary shaft and, through a dog clutch, to either gear 1 or gear 3 , and an 
'even' electric machine, which is connected to the 'even' primary shaft and, through a dog clutch, to either gear 2 or gear 4 . The gearshifts can be entirely operated through the control of the electric motor drive torques and the position of the electro-mechanical dog clutch actuators which drive barrel cams to select the gears. The high controllability inherent to electric motor drives permits the actuation of the gearshifts without the need for synchronisers, as the synchronisation is carried out electrically. This transmission can be coupled to a torque vectoring differential, therefore providing the energy efficiency benefit of a multiple-speed transmission and the vehicle dynamic performance of individual wheel powertrains, which have the packaging and weight-related constraint of being characterised by a single-speed transmission. The dual-motor layout of this novel drivetrain concept allows a high load factor of the electric machines, when they are operated singularly, with a further potential increase of the overall energy efficiency depending on the motor characteristics.

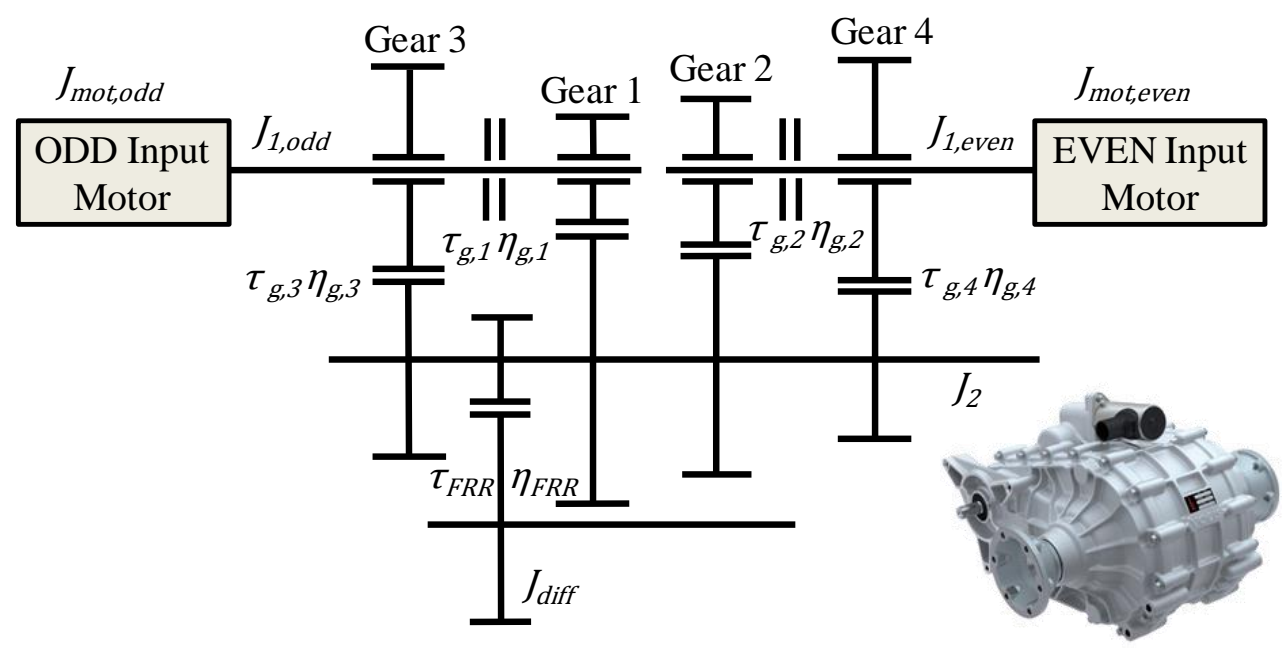

Figure 1 -Schematic of the drivetrain concept, with a rendered 3D image of the final version included as an inset

Nine possible states characterise the system operating conditions: 1) only first gear engaged; 2) only second gear engaged; 3) only third gear engaged; 4) only fourth gear engaged; 5) first and second gears engaged; 6) second and third gears engaged; 7) third and fourth gears engaged; 8) first and fourth gears engaged; and 9) no engaged gear. However, the prototype transmission is incapable of operating in state 8, first and fourth gear, although it is considered for the research presented in this paper.

The adoption of this transmission layout implies a significant increase in flexibility when selecting the electric motor drives operating points. For example, Figure 2 plots the theoretical wheel torque obtainable in steady-state conditions (i.e. neglecting the angular acceleration of the drivetrain components and hence their inertial effects), at the peak torque of 
the electric motor drive/s, as a function of vehicle longitudinal velocity, for each possible state of the dual-motor drivetrain for a case study vehicle. Transmission efficiency has been neglected for simplicity in this single figure but it will be considered in the calculations presented in the next sections of the contribution. The wheel torque characteristic can be subdivided into fifteen different areas (from A to O), each of which can be covered by a different number of states. The higher the number of states which can generate the same wheel torque and vehicle speed combination, the larger is the chance of being able to achieve a higher operating efficiency of the overall system. The number of alternative operating states of the drivetrain for each area is outlined in Table 1. In particular, for low torque and low speed conditions, the transmission permits the alternative selection of eight states (area $\mathrm{H}$ ), whilst a significant number of alternatives is also allowed in further driving conditions. For example, in the torque envelope enclosing areas D-E-F-G-H-L-N, covered during normal driving conditions, at least three alternative states are selectable for each operating point. Due to the constant power characteristic of the electric motor drives, even operating points located at the peak torque levels, such as those in the areas $\mathrm{J}, \mathrm{K}$ and $\mathrm{M}$, can be covered by multiple alternative states.

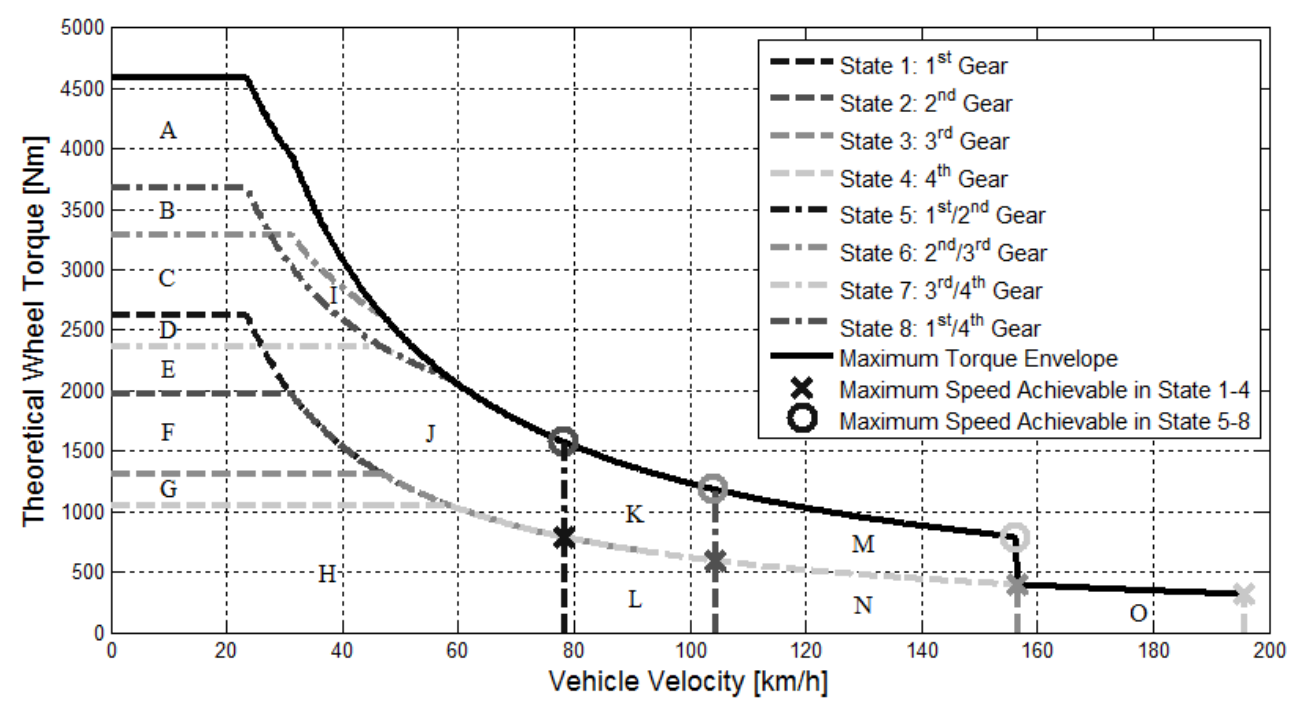

Figure 2 - Theoretical wheel torque as a function of vehicle velocity for the different transmission states 
Table 1 - Number of possible states (second row of the table) which can generate the operating condition outlined in each sub-area (identified by the first row of the table) of Figure 1

\begin{tabular}{llllllllllllllll}
\hline $\boldsymbol{A}$ & $\boldsymbol{B}$ & $\boldsymbol{C}$ & $\boldsymbol{D}$ & $\boldsymbol{E}$ & $\boldsymbol{F}$ & $\boldsymbol{G}$ & $\boldsymbol{H}$ & $\boldsymbol{I}$ & $\boldsymbol{J}$ & $\boldsymbol{K}$ & $\boldsymbol{L}$ & $\boldsymbol{M}$ & $\boldsymbol{N}$ & $\boldsymbol{O}$ \\
\hline 1 & 2 & 3 & 4 & 5 & 6 & 7 & 8 & 2 & 5 & 4 & 5 & 2 & 3 & 1 \\
\hline
\end{tabular}

\section{The Electric Drivetrain Dynamic Model}

Firstly, this paragraph will describe the equations for modelling the dynamics of the novel transmission system and go on to deal with the modelling principles of the overall vehicle longitudinal dynamics.

The transmission can work in conditions of: i) no engaged gear on either primary shaft; ii) one engaged gear on one primary shaft and no engaged gear on the other primary shaft; and iii) two engaged gears, one per each primary shaft. As a consequence, each primary shaft is characterised either by an engaged gear and a disengaged gear or by two disengaged gears. If a gear is engaged, the primary shaft on which that gear is located will rotate with a constant gear ratio relative to the other components of the transmission, in particular the secondary shaft of the transmission and the differential case (if we neglect the mechanical play within the system). If both gears of the same primary shaft are disengaged, the electric motor shaft and the transmission primary shaft will rotate independently from the rest of the transmission. Therefore the overall system can be characterised by up to three degrees of freedom, one in case of an engaged gear for each primary shaft, and three in case of a condition of two disengaged gears on each primary shaft.

The torque balance equation of the generic primary shaft (including the electric motor) when it constitutes an independent degree of freedom (two disengaged gears on that shaft) is given by:

$T_{\text {mot,odd/even }}-T_{\text {loss,odd/even }}=\left(J_{\text {mot,odd/even }}+J_{1, \text { odd/even }}\right) \ddot{\vartheta}_{\text {mot }, \text { odd } / \text { even }}$

The torque contribution $T_{\text {loss,odd/even }}$ is particularly important, as it contributes to the decay rate of motor speed when either motor is disengaged from the rest of the drivetrain. The electric motor drive torque $T_{\text {mot,odd/even }}$ takes into account the air gap torque dynamics with respect to the reference theoretical air gap torque (function of torque demand and electric motor speed) through a second order differential equation (or transfer function), and also the contribution caused by the 
windage losses of the electric motor drive, which are expressed by a look-up-table as a function of motor shaft speed, equations (2) and (3).

$$
\begin{array}{r}
T_{\text {mot,odd/even }}=T_{\text {mot,del,odd/even }}-T_{\text {windage,odd/even }}\left(\dot{\vartheta}_{\text {mot }, \text { odd/even }}\right) \\
T_{\text {mot,del.odd/even }}=T_{\text {mot,ref,odd/even }}\left(\dot{\vartheta}_{\text {mot,odd/even }}, T D_{\text {mot,odd/even }}\right) . \\
\cdot \frac{1}{1+\frac{2 \zeta_{\text {mot }, \text { odd/even }}}{\omega_{n, \text { mot,odd/even }}}+\frac{s^{2}}{\omega_{n, \text { mot }, \text { odd/even }}^{2}}}
\end{array}
$$

During a gearshift, when the angular speed difference between the electric motor shaft and the differential (referred back to the motor shaft) remains close to zero for a required amount of time, the gear is engaged and the system loses a mechanical degree of freedom, therefore equation (1) becomes irrelevant to the system dynamics, as it is incorporated into the overall torque balance equation at the differential. If the gear is disengaged during a gearshift, equation (1) is relevant again and is re-activated by resetting the initial conditions of the integral operator. This calculates the angular velocity of the primary shaft starting from its acceleration, by using as initial condition the last value of the motor shaft speed (calculated from the differential speed) before the disengagement of the dog clutch. The dog clutch actuator position is modelled through a time delay and a first order transfer function, equation (4). This method allows to accurately simulate the physical properties of the actuator experimentally attained on the prototype transmission.

$x_{\text {gear }, a c t}(t)=x_{\text {gear }, \text { ref }}\left(t-\tau_{\text {gear,act }}\right) \frac{\frac{1}{T_{\text {gear }, a c t}}}{1+\frac{s}{T_{\text {gear }, a c t}}}$

$T_{\text {gear,act }}$ assumes different values depending on the direction of motion of the actuator, mimicking the experimental behaviour.

Equation (5) is the first approximation torque balance equation of the transmission components rotating together with the differential. Only one comprehensive formulation of the equation is reported here, despite each of the nine states of transmission operation requiring a unique variation of this equation. The variables flag $_{\text {sel.even/odd }}$ are adopted to indicate whether a gear is engaged on the 'even' and/or 'odd' primary shaft, in order to include (in case of engaged gear) or exclude (in case of disengaged gear) the relating electric motor torque and the inertias of the motor, engaged gear and primary shaft within equation (5). 


$$
\begin{aligned}
& T_{\text {mot,even }} \tau_{g, \text { sel,even }} \eta_{g, \text { sel,even }} \tau_{F R R} \eta_{F R R} \text { flag }_{\text {sel.even }}+ \\
& +T_{\text {mot,odd }} \tau_{g, \text { sel,odd }} \eta_{g, \text { sel,odd }} \tau_{F R R} \eta_{F R R} \text { flag } \text { sel.odd }+ \\
& -T_{H S, L}-T_{H S, R}= \\
& =\left[J_{\text {diff }}+J_{2} \tau_{F R R}^{2} \eta_{F R R}+\frac{\sum J_{g, \text { unsel }, \text { even }} \tau_{g, \text { unsel }, \text { even }}^{2} \tau_{F R R}^{2} \eta_{F R R}}{\eta_{\text {g,unsel,even }}}+\right. \\
& +\frac{\sum J_{g, \text { unsel }, \text { odd }} \tau_{\text {g,unsel }, \text { odd }}^{2} \tau_{F R R}^{2} \eta_{F R R}}{\eta_{\text {g,unsel,odd }}}+ \\
& +\left(J_{\text {mot,even }}+J_{1, \text { even }}+J_{g, \text { sel,even }}\right) \text { flag } \operatorname{sel.even}_{\text {g,sel,even }} \eta_{g, \text { sel }, \text { even }} \tau_{F R R}^{2} \eta_{F R R}+ \\
& \left.+\left(J_{\text {mot }, \text { odd }}+J_{1, \text { odd }}+J_{g, \text { sel,odd }}\right) \text { flag }_{\text {sel,odd }} \tau_{g, \text { sel,odd }}^{2} \eta_{g, \text { sel,odd }} \tau_{F R R}^{2} \eta_{F R R}\right] \ddot{\vartheta}_{\text {diff }}
\end{aligned}
$$

The efficiency map of the transmission to be adopted in equation (5) has been derived from detailed models of the different transmission efficiency contributions available at the industrial company supporting this research and experimentally validated on other transmission systems with comparable mechanical characteristics. This model includes the contributions deriving from the bearings, the gear meshing, the windage and churning, and also the actuation losses. However, the efficiency values adopted for equation (5) do not include the losses due to the electro-mechanical actuation of the dog clutches, which are localised during the gearshift actuation phase. The efficiencies in equation (5) represent equivalent values and are split between the 'odd' side of the gearbox, the 'even' side of the gearbox and the final reduction gear. The efficiency of each contribution is computed as a function of the respective input torque to the transmission, primary shaft angular speed and operating temperature. The efficiencies in equation (5) have been considered for traction conditions of the powertrain, and can be reversed in case of a different sign of the input torque to the gear couplings. A lumped parameter model (i.e. equivalent thermal capacity with internal heat generation and heat exchange with the external ambient and adjacent components) of the transmission and each electric motor drive permits the estimation of the temperature dynamics of the system.

The transmission system model has been coupled with a vehicle longitudinal dynamics model, similar to the one presented in (Sorniotti et al., 2012) and (Holdstock et al., 2012). The quality of the gearshift can only be evaluated through a model which at least considers the first order drivetrain torsion dynamics. In conditions of engaged gears, the overall drivetrain can be thought of as a system of one equivalent inertia (from the motors to the differential) connected to the wheel inertia (the second inertia of the overall system, an equivalent wheel inertia per axle can be considered) through the half-shafts, modelled as torsion springs and 
dampers. The plays in the drivetrain system are distributed between the dog clutches, the gear between the primary and secondary shaft, the gear between the secondary shaft and the differential case, the differential mechanism (planetary gears and sun gears) and the constant velocity joints. The plays in the different components have the same order of magnitude (a few decimals of a degree), but their significance is higher when they are located in close proximity to the wheels. The dynamic model implemented here considers an equivalent play of the transmission, located at the transmission output, between the inner constant velocity joints and the halfshaft. In formulas:

$T_{H S, L / R}=k_{H S, L / R} \Delta \vartheta_{\text {diff-w,eq }}+c_{H S, L / R} \Delta \dot{\vartheta}_{\text {diff-w,eq }}$

where:

$$
\begin{aligned}
& \Delta \vartheta_{\text {diff }-w, e q}= \\
& =\left\{\begin{array}{c}
0, \text { if }\left|\vartheta_{w}-\vartheta_{\text {diff }}\right|<\Delta \vartheta_{\text {play }} \\
\left(\left|\vartheta_{w}-\vartheta_{\text {diff }}\right|-\Delta \vartheta_{\text {play }}\right) \operatorname{sign}\left(\vartheta_{w}-\vartheta_{\text {diff }}\right), \text { if }\left|\vartheta_{w}-\vartheta_{\text {diff }}\right|>\Delta \vartheta_{\text {play }}
\end{array}\right.
\end{aligned}
$$

The dual-motor drivetrain can be coupled to either an open differential or a torque vectoring differential. Differential dynamics can be included or excluded depending on the purpose of the specific simulation run. Tyre longitudinal dynamics are modelled through the well-known Pacejka magic formula and a relaxation length model (Pacejka, 2006).

If either the 'even' or 'odd' primary shaft is not characterised by an engaged gear, the equivalent mass moment of inertia of the drivetrain is subject to a reduction, as it loses the contribution related to that side of the transmission. During the transition between the different transmission states, the mass moment of inertia of the wheel and the torsion dynamics (due to the stiffness and marginally the damping coefficient) of the half-shaft remain the same, however the variation of the equivalent inertia of the drivetrain provokes a variation of the dynamic response of the system. This variation is not as evident as in a conventional manual transmission of an internal combustion engine driven vehicle, due to the fact that in the dual-motor drivetrain at least one electric motor drive (the motors are the major contributors to system inertia) usually remains engaged to the transmission output during a gearshift.

In the next paragraphs the drivetrain system will be simulated and tested on two case study vehicle applications, whose data sets are in Appendix A. The two vehicles are a rear wheel driven high performance sedan (case A) and a front wheel driven city car (case B) where each vehicle is equipped with very different motor drives. The first vehicle (case A) is equipped with an 
electric motor drive characterised by a limited angular speed range (maximum motor speed of 5,000 rpm) and a very wide constant torque region, whilst the second vehicle (case $\mathrm{B}$ ) is equipped with an electric motor drive characterised by a high value of maximum speed $(14,000 \mathrm{rpm})$ and a limited extension of the constant torque region. Table 2 reports the value of the equivalent mass moment of inertia (and the relating contribution to the vehicle apparent mass) of the dual motor drivetrain (from the motors to the wheels) for each state, for the two case study vehicles. In low gear conditions for vehicle $\mathrm{B}$, characterised by a low mass and a low torque electric motor drive, the contribution of the drivetrain rotating components to the vehicle apparent mass is particularly relevant.

Table 2 - Mass moment of inertia (first row for each vehicle, expressed in $\mathrm{kgm}^{2}$ ) of the rotating components of the electric drivetrain referred to the differential (and subsequent variation of vehicle apparent mass, in the second row for each case study vehicle, expressed in $\mathrm{kg}$ ), as a function of the drivetrain state (transmission efficiency has been neglected in this calculation, but is considered in the formulas adopted in the simulator)

\begin{tabular}{llllllllll}
\hline State & $\mathbf{1}$ & $\mathbf{2}$ & $\mathbf{3}$ & $\mathbf{4}$ & $\mathbf{5}$ & $\mathbf{6}$ & $\mathbf{7}$ & $\mathbf{8}$ & $\mathbf{9}$ \\
\hline Case study vehicle A & 7.5 & 4.8 & 2.7 & 2.7 & 10.1 & 5.3 & 3.2 & 8.0 & 2.2 \\
& 70 & 45 & 25 & 25 & 95 & 49 & 30 & 75 & 20 \\
\hline Case study vehicle B & 7.6 & 6.5 & 3.9 & 2.6 & 11.8 & 8.1 & 4.3 & 8.0 & 2.2 \\
& 79 & 67 & 40 & 27 & 123 & 85 & 45 & 83 & 23 \\
\hline
\end{tabular}

A linearised and simplified (e.g. first order dynamics for the electric motor drive) model of the system has been implemented for each operating state, according to a state-space formulation (Nise, 2004). The main non-linearity to be considered is the longitudinal tyre response characteristic. Therefore the longitudinal slip stiffness is calculated for each operating state, considering the value of vertical load and slip ratio (a function of the expected wheel torque) for the specific linearisation point, through the Pacejka tyre model. A first linearisation of the tyre longitudinal force vs. slip ratio characteristic is carried out, followed by a second linearisation of the slip ratio as a function of wheel speed and vehicle equivalent angular speed. In formulas:

$$
\begin{aligned}
& T_{T, \text { theor }}=F_{x, \text { theor }} R_{W} \cong F_{x 0, \text { theor }} R_{w}+C_{s} \frac{\dot{\vartheta}_{w}-\dot{\vartheta}_{v}}{\dot{\vartheta}_{w}} R_{w}-C_{s} \frac{\dot{\vartheta}_{w, 0}-\dot{\vartheta}_{v, 0}}{\dot{\vartheta}_{w, 0}} R_{w} \\
& \cong F_{x 0, \text { theor }} R_{w}+\frac{C_{s} R_{w}}{\dot{\vartheta}_{w_{0}}}\left(\frac{\dot{\vartheta}_{v_{0}}}{\dot{\vartheta}_{w_{0}}} \dot{\vartheta}_{w}-\dot{\vartheta}_{v}\right)
\end{aligned}
$$

The tyre relaxation parameter is considered constant in the linearised model. In actual operating conditions (excluding cornering), this parameter is a 
function of the slip ratio and tyre vertical load. The equations of the matrices derived for the state-space formulation are summarised in Appendix B.

Figures 3-5 plot the adimensional frequency response characteristics of vehicle acceleration, where the adimensionalisation has been carried out through the steady-state value of the response. As the system is characterised by multiple inputs, the derivation of the vehicle acceleration frequency response is carried out through the combination of the resultant responses caused by the single inputs to the system. In particular, the reference 'odd' motor torque and the reference 'even' motor torque are combined through equation (9). The motor reference torques are considered to be phase synchronous.

$\left|A_{x}\right|=\sqrt{\left(\sum_{i=1}^{n_{\text {input }}}\left|A_{x, i}\right| u_{i} \cos \varphi_{i}\right)^{2}+\left(\sum_{i=1}^{n_{\text {input }}}\left|A_{x, i}\right| u_{i} \sin \varphi_{i}\right)^{2}}$

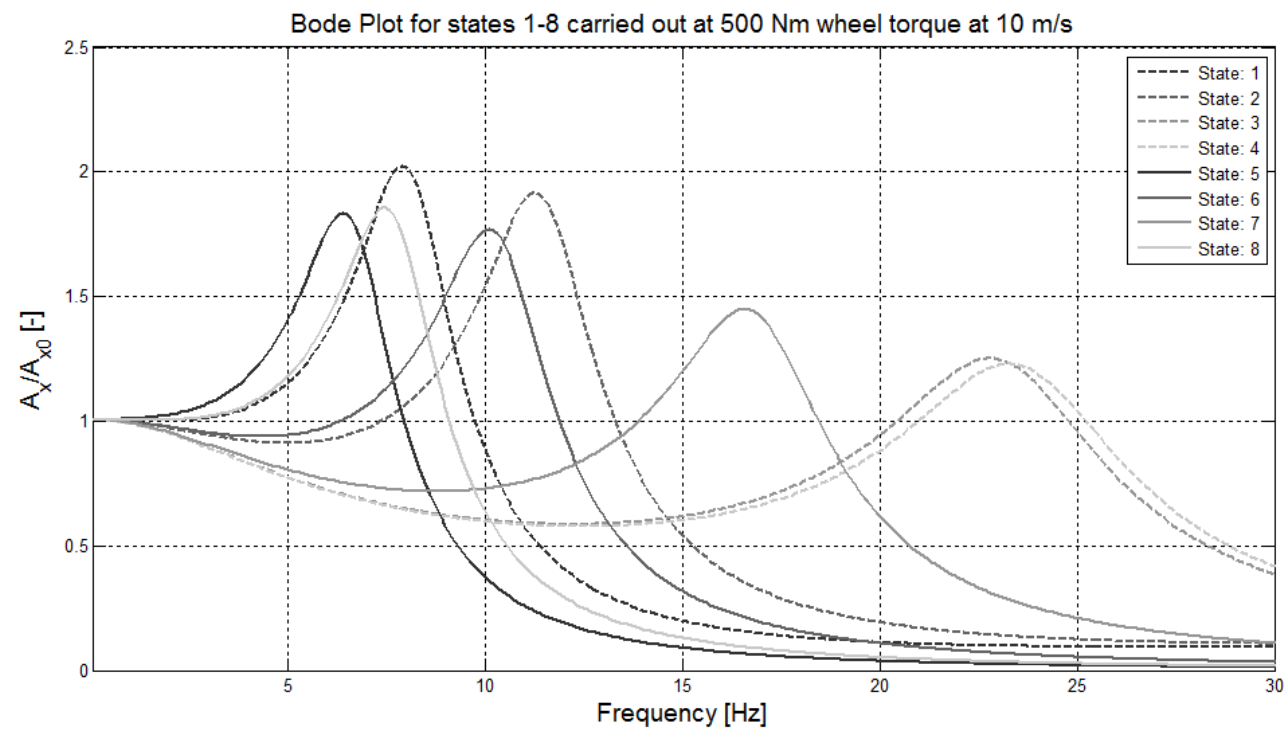

Figure 3 - Frequency response characteristic of the adimensional vehicle acceleration for states 1-8 of case study vehicle A, for the same operating condition $(500 \mathrm{Nm}$ of wheel torque at a vehicle speed of $10 \mathrm{~m} / \mathrm{sec}$ )

The response of the system can be strongly underdamped, with a variation of the first natural frequency (Figure 3) consistent with the values of the equivalent mass moment of inertia of the drivetrain shown in Table 2. The value of the damping ratio of the first mode of the system is an increasing function of the vehicle longitudinal velocity and wheel torque (which provokes a variation of the linearised longitudinal slip stiffness). 


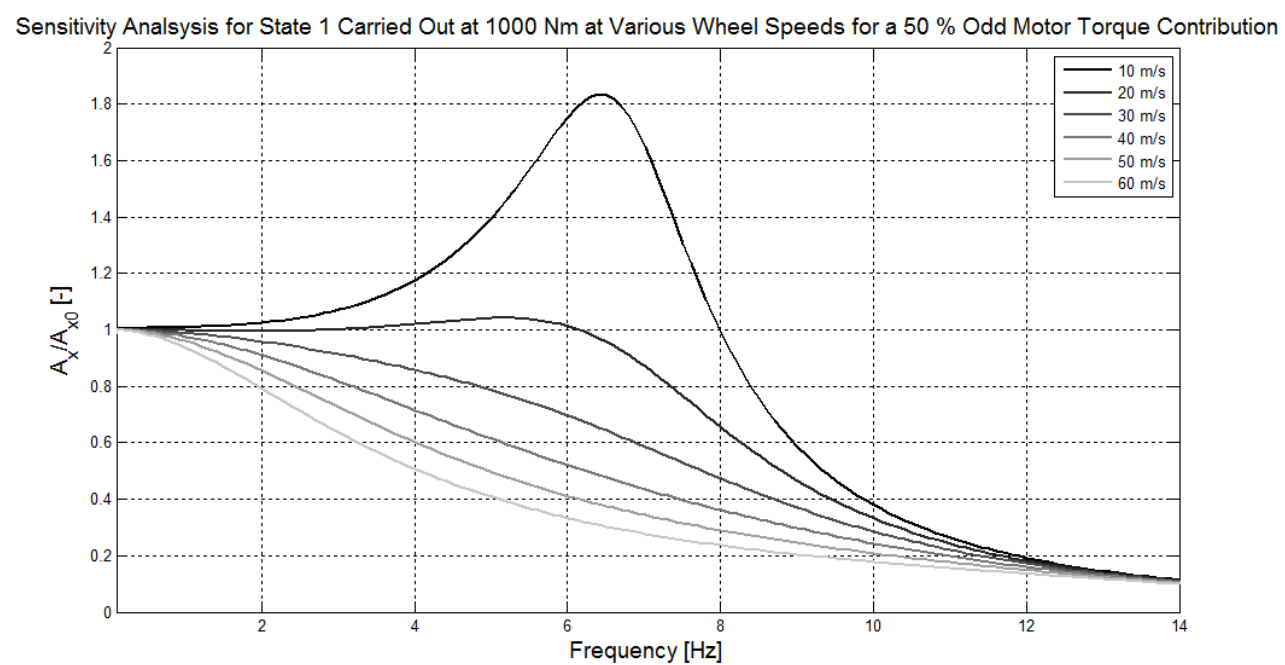

Figure 4 - Frequency response characteristic of the adimensional vehicle acceleration for state 1 of case study vehicle A, for different values of vehicle longitudinal velocity and $1,000 \mathrm{Nm}$ of wheel torque where the motor torque referred to the wheels is the same for each motor

The frequency response of the system is substantially independent from the torque distribution between the two electric motor drives, provided that their air gap torque dynamic characteristics are not significantly different. This property differentiates the dynamic characteristics of this novel drivetrain from those of a typical parallel hybrid electric vehicle, where the torque distribution between engine and electric motor heavily affects the drivability response.

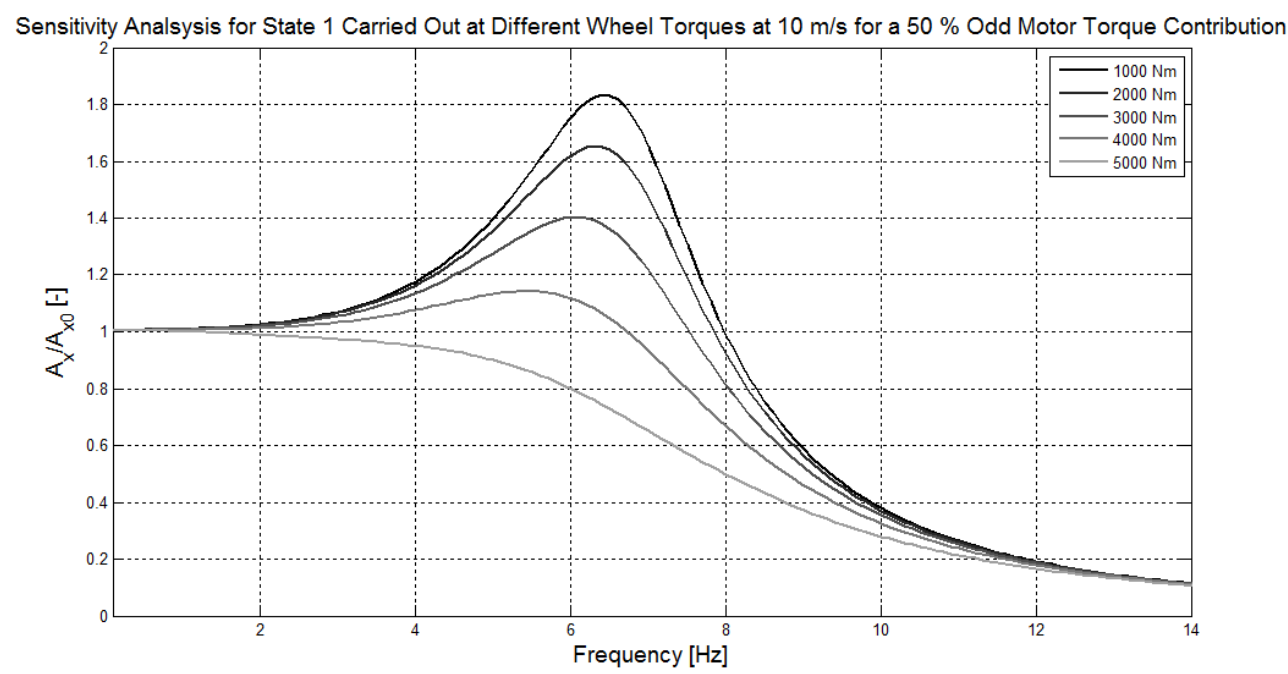

Figure 5 - Frequency response characteristic of the adimensional vehicle acceleration for state 1 of case study vehicle $A$, for different values of wheel torque, at a vehicle speed of $10 \mathrm{~m} / \mathrm{sec}$ where the motor torque referred to the wheels is the same for each motor 


\section{Gearshift Control}

This section describes the seamless gearshift dynamics of the system, implemented on the non-linear model described in the previous section. In particular, several cases can be outlined: i) power-on upshift from a dual gear condition to another dual gear condition (i.e. from first and second gear to second and third gear); ii) power-off upshift in dual gear condition; iii) power-on downshift in dual gear condition; iv) power-off downshift in dual gear condition; v) the same cases as in i)-iv) in conditions of single-gear. The transitions from a dual gear condition to a single-gear condition and vice versa are a particular variant of case i). The next section will provide a detailed analysis of case i) and the equivalent of i) for a single-gear to single-gear state shift.

Initially, in condition of engaged gear (or gears), an energy management system (EMS) calculates the torque demand of each electric powertrain depending on the current drivetrain state and driver torque demand. The energy management system achieves this through initially setting a theoretical reference wheel torque $T_{w, r e f}(V, T D)$ as a function of vehicle velocity and driver torque demand expressed in percentage of the maximum available wheel torque. The maximum available wheel torque is computed from a look-up-table containing the envelope of the characteristics in Figure 2. For each reference wheel torque $T_{w, r e f}$ and vehicle velocity $V$, a look-up-table outputs the selected reference torque $T_{\text {ref,odd,EMS }}$ for the 'odd' electric motor drive, which can be tuned off-line according to an energy efficiency criterion. The reference torque $T_{\text {ref,even,EMS }}$ calculated by the EMS on the 'even' motor drive is:

$T_{\text {ref,even,EMS }}=\frac{T_{w, \text { ref }}(V, T D)-T_{\text {ref,odd,EMS }}(V, T D, \text { state }) \tau_{g, \text { sel }, \text { odd }}(V, T D) \tau_{F R R}}{\tau_{g, \text { sel }, \text { even }}(V, T D) \tau_{F R R}}$

The gearshift strategy controls the position of the gear actuators and, during gearshift actuation, supersedes the electric motor torque demands $T_{\text {ref,odd,EMS }}$ and $T_{\text {ref,even,EMS }}$ calculated by the energy management system.

\subsection{Upshift from Dual Gear State to Dual Gear State in Power-on}

An upshift from a dual gear to another dual gear state in power-on is presented in Figure 6 (regarding a $1^{\text {st }}-2^{\text {nd }}$ to $2^{\text {nd }}-3^{\text {rd }}$ upshift), in which the manoeuvre is split into functional phases (from A to G). Firstly (phase A), the system carries out a torque roll-off phase (at a rate which depends on the tuning of the controller for the specific vehicle application) on the electric motor drive on the transmission side involved in the gearshift (the 'odd' motor drive in Figure 6). This is compensated by a torque increase on the other electric motor drive (the 'even' motor drive in the specific manoeuvre), with the aim of providing the desired vehicle acceleration 
profile during the upshift. In particular, the compensation takes into account the difference between the reference torque contributions at the wheel for the electric motor drive involved in the gearshift $\left(T_{w, \text { ref, mot gearshift,EMS }}\right)$, and the actual estimated wheel torque $T_{w, \text { roll-off }}$ transmitted by the same motor unit to the wheel. In formulas:

$T_{\text {ref, mot constant gear, roll-off comp }}=$

$=\frac{T_{w, \text { ref,mot gearshift }, E M S}(V, T D)-T_{w, \text { roll-off }}+T_{w, \text { ref }, \text { mot constant gear }, E M S}}{\tau_{g, \text { mot constant gear }} \tau_{F R R}}$

A detailed estimation of the actual wheel torque at the wheels can include the inertial parameters of the transmission (the same statement is valid for the torque contributions in equation (10)); however for a basic implementation of the system, the inclusion of the gear ratio only in the estimation process is a sufficient approximation for an acceptable gearshift. Once the electric motor drive torque on the transmission side involved in the upshift has gone to zero, the reference signal is sent to the respective gear actuator (phase B of Figure 6). Once the dog clutch has been disengaged (phase $\mathrm{C}$ of Figure 6), a combination of a feedforward and a Proportional Integral Derivative (PID) controller is used for the speed control of the electric motor drive on the drivetrain side involved in the gearshift.

In this phase, the dynamic torque balance equation of the electric motor drive can be linearised by modelling the windage loss (on the motor and transmission primary shaft) contribution as a viscous damping contribution with damping coefficient $b_{m o t}$. The resulting loop-gain transfer function for the feedback control system is:

$$
\begin{aligned}
& \frac{\overline{\hat{\vartheta}}_{\text {mot }}}{\overline{\bar{T}}_{\text {motor,theor }}}= \\
& =\frac{G_{P I D}(s)}{\frac{J_{m o t}}{\omega_{n, m o t}^{2}} s^{3}+\left(\frac{2 \zeta_{m o t} J_{m o t}}{\omega_{n, m o t}}+\frac{b_{m o t}}{\omega_{n, m o t}^{2}}\right) s^{2}+\left(J_{m o t}+\frac{2 \zeta_{m o t} b_{m o t}}{\omega_{n, m o t}}\right) s+b_{m o t}}
\end{aligned}
$$

The gains of the feedback controller can be tuned by using the conventional methodologies based on stability (gain margin and phase margin) and performance (tracking bandwidth). A sensitivity analysis of the system response to the variation of the proportional gain of the motor speed controller is shown in Figure 7. The structure of the motor speed controller is only marginally relevant, as the controller has an impact on the motor speed dynamics when the respective dog clutch is disengaged. As a consequence, the resulting dynamics do not directly affect vehicle response. 
Int. J. of Powertrains, Vol. $x$, No. $x$, xxxx
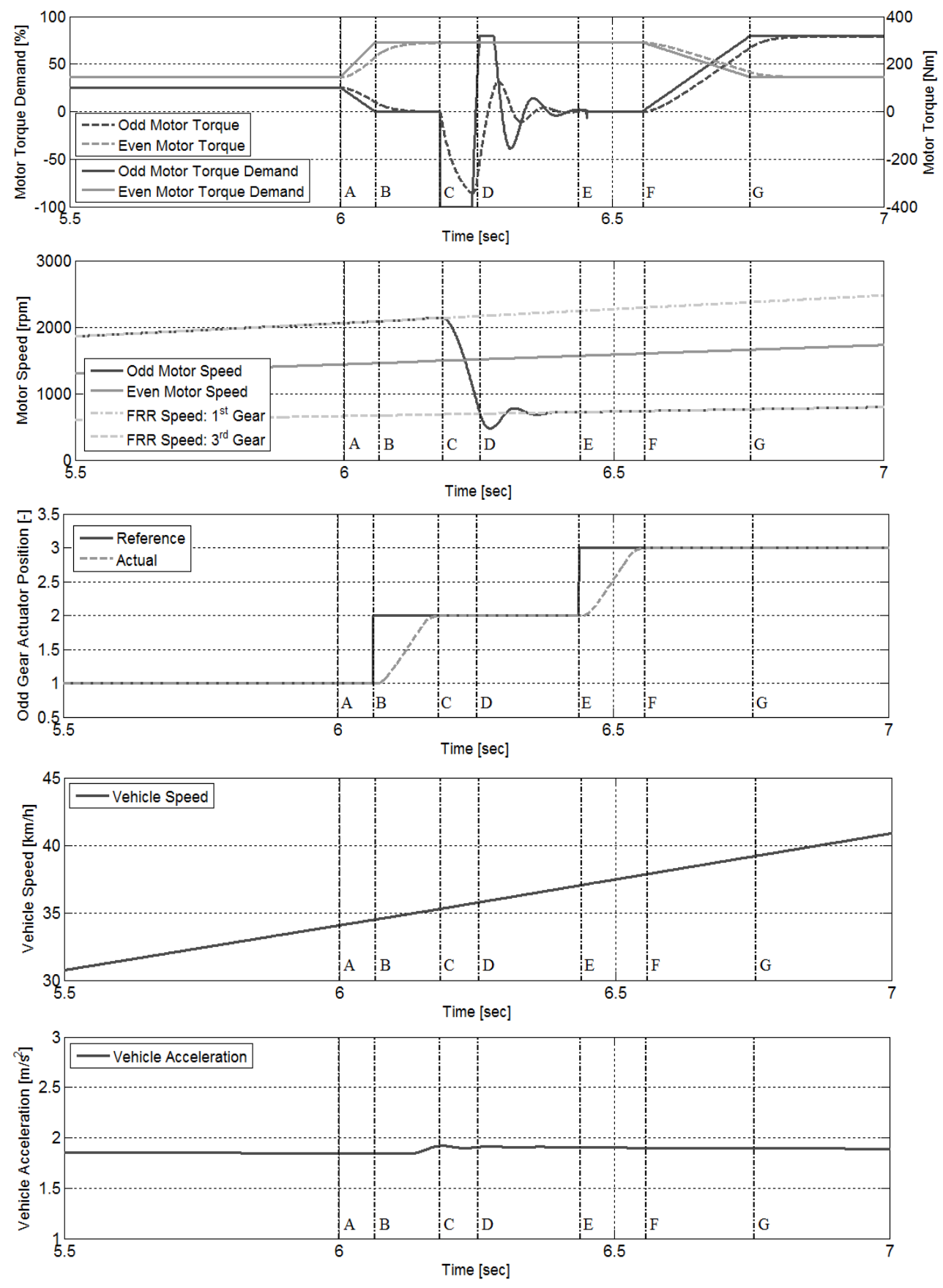

Figure 6 - Example of upshift from $1^{\text {st }}-2^{\text {nd }}$ to $2^{\text {nd }}-3^{\text {rd }}$ in condition of $30 \%$ driver torque demand for vehicle $\mathrm{A}$ 

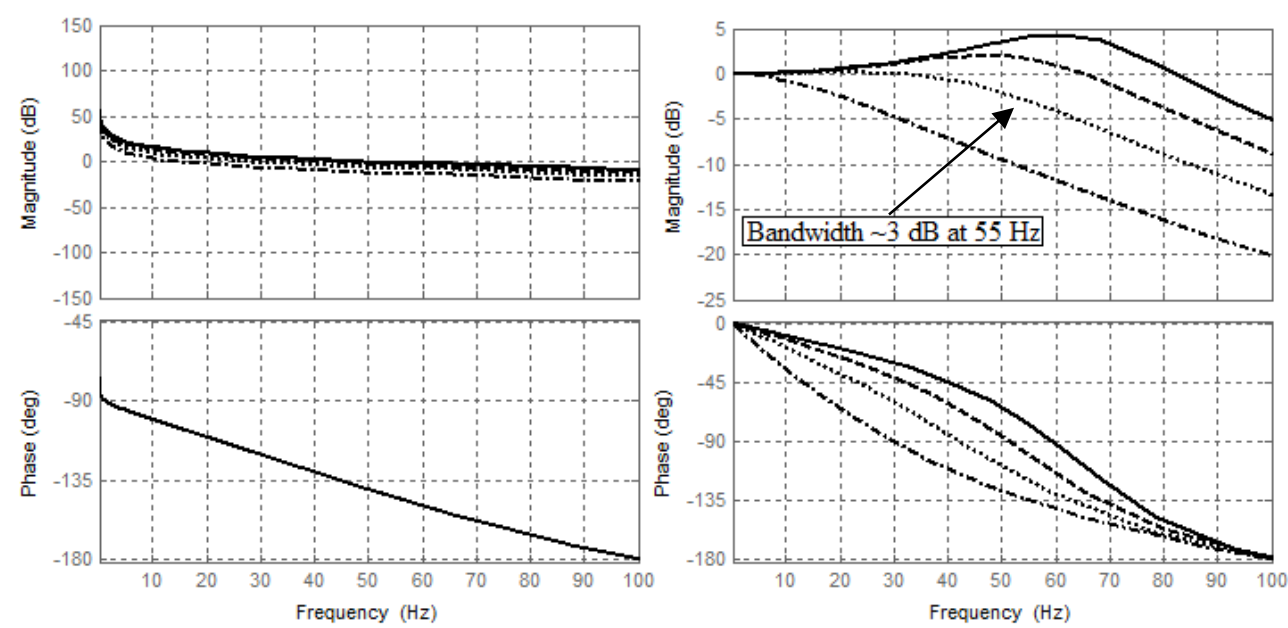

Figure 7 - Bode plots of the loop-gain transfer function (on the left) and closed-loop transfer function (on the right) for different tuning parameters (proportional gain) of the electric motor drive PID controller (case study vehicle A)

When the difference between the actual motor speed and the reference motor speed in the new gear $\left(3^{\text {rd }}\right.$ gear in Figure 6$)$ is within a threshold (for example, $75 \mathrm{rpm}$ ), a counter is started (phase D of Figure 6). After the error between the reference motor speed and the actual motor speed remains within the threshold for a sufficient amount of time (for example, 100 $\mathrm{msec}$ ), the dog clutch actuator is re-engaged on the next gear (phase E of Figure 6). Once the actuator has reached the reference position (new gear engaged), the reference motor torque on the drivetrain side involved in the gearshift is ramped up to the value specified by the energy management system, whilst equation (10) is used for the derivation of the motor drive torque on the other side of the drivetrain.

Figure 8 is the comparison of the acceleration profiles during $1^{\text {st }}-2^{\text {nd }}$ to $2^{\text {nd }}-3^{\text {rd }}$ upshifts for different driver torque demands, $30 \%$ and $50 \%$, and different distributions of the torque between the two electric powertrains. In particular, a $50 / 50$ distribution at the wheels (' $50 \%$ Distribution' in the figure) is compared with a wheel torque distribution directly proportional to the respective gear ratio ('GR Distribution' in the figure). The latter permits the system to achieve the same motor torque demand for the two drivetrain halves before and after the gearshift manoeuvre, in the constant torque region of the two identical machines. 


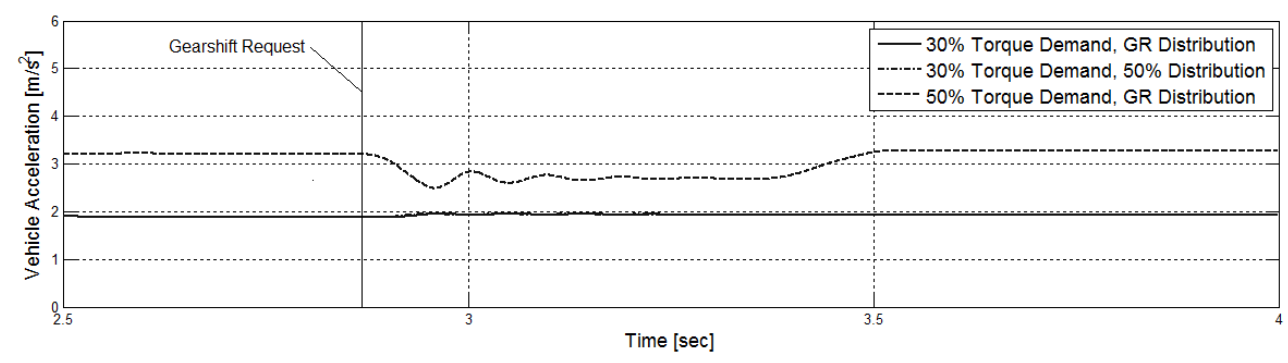

Figure 8 - Comparison of the vehicle acceleration profiles for different wheel torque distributions and torque demands

The plot shows that the initial and final torque distributions do not affect the gearshift dynamics of the system, i.e. the system is robust against the motor torque distribution variations specified by the energy management system. Moreover, it is evident that for higher torque demands a torque gap is generated during the gearshift because of the saturation of the torque on the electric motor drive that compensates the torque roll-off phase of the powertrain half subject to the upshift.

\subsection{Upshift from Single-Gear State to Single-Gear State in Power-on}

Figure 9 is an example of an upshift from a single-gear condition to another single-gear condition $\left(1^{\text {st }}\right.$ to $2^{\text {nd }}$ in the specific case). The first step (phase A) in the procedure is the speed control (electric synchronisation) of the electric motor drive which is going to be characterised by the final gear ratio, through the same combination of feedforward and feedback control of the motor discussed for the previous manoeuvre. Once the error between the reference and the actual motor speed is within a threshold (phase B) for a specified amount of time, the dog clutch actuator can be moved (phase C) to engage the new gear, following which the reference torque level of the electric motor drive on the new gear side can be ramped up (phase D), whilst the reference torque of the electric motor drive on the other side of the transmission is ramped down, similarly to what is presented in equation (10).

Both upshift manoeuvres of Figure 6 and Figure 9 are characterised by a substantially seamless actuation, which is evident from the speed and acceleration profiles in the respective figures. Seamless upshifts in dual gear conditions can be achieved only when the system operates at a significantly lower torque demand than the maximum allowed level. Similar control methodologies have been applied to the control of the other possible combinations of upshifts and downshifts. 
Int. J. of Powertrains, Vol. $x$, No. $x, x x x x$
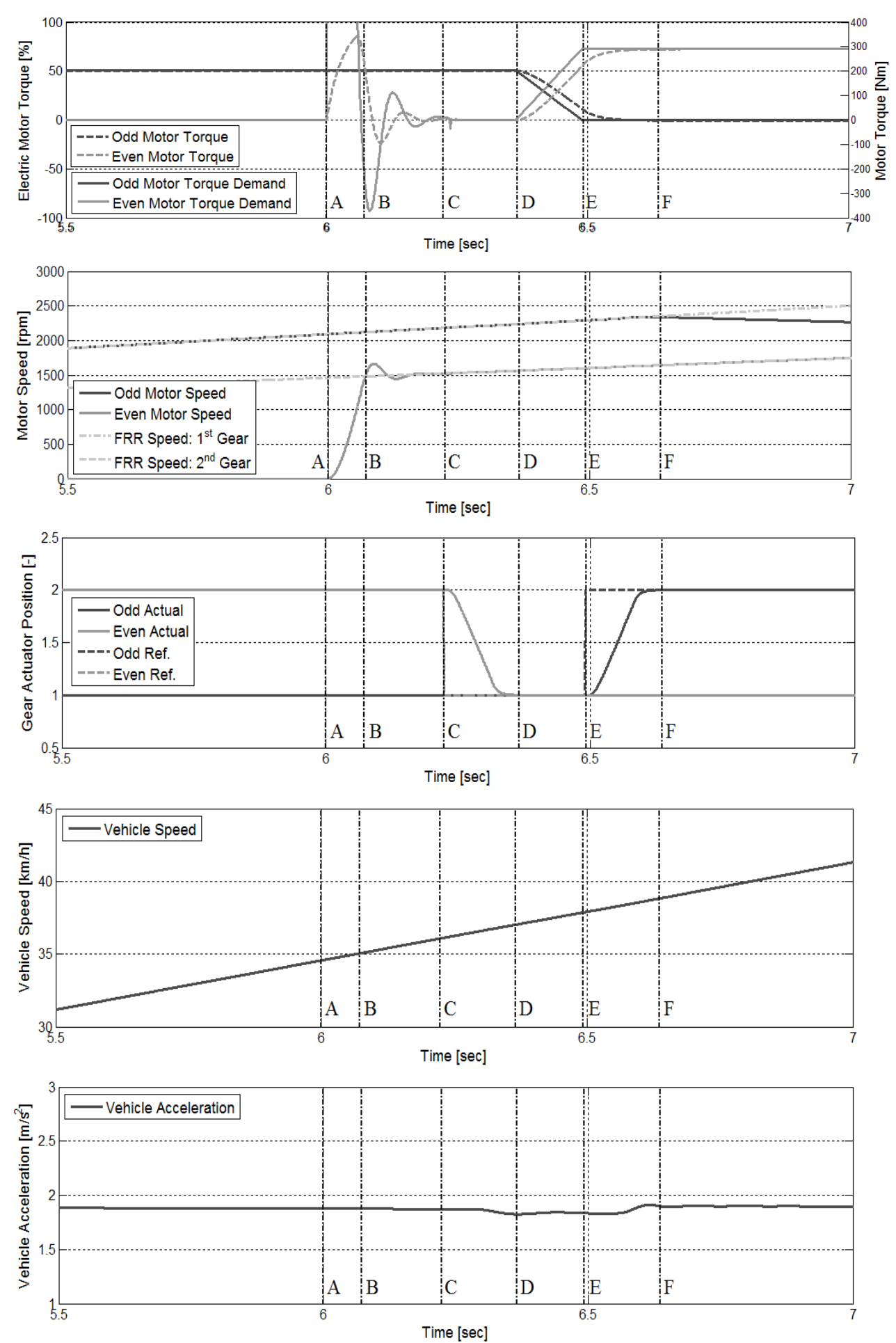

Figure 9 - Example of upshift from $1^{\text {st }}$ to $2^{\text {nd }}$ in conditions of $30 \%$ driver torque demand for vehicle $\mathrm{A}$ 


\section{Energy Efficiency and Overall Performance Evaluation}

This section provides an insight into the methodologies used for the evaluation of the overall vehicle performance in conjunction with the adoption of the novel dual-motor drivetrain. The results are compared with those of other electric drivetrain configurations, such as the commonly adopted single-speed and double-speed electric drivetrains with central electric motor drive and differential. Firstly, the methodology implemented for the selection of the most efficient state (i.e. the equivalent of the gearshift map for a single-motor multiple-speed drivetrain) and torque distribution between the two electric machines for each driving condition is presented. Then simulation results and performance metrics are analysed and discussed.

\subsection{State Selection}

This paragraph explains the automated off-line procedures, partially summarised in Figure 10, which have been developed for the selection of the optimal (i.e. the most energy efficient) operating state and torque demand distribution between the two electric motor drives, for assigned values of wheel torque demand and vehicle velocity.

For a value of wheel torque, vehicle speed, drivetrain thermal condition (transmission and electric motor/s temperatures) and drivetrain state, the routine estimates the value of vehicle acceleration for the analysed road grade. Road grade is assumed equal to zero in the results presented in this article. If road grade can be estimated on-line during vehicle operation, the procedure should be repeated for the range of different road grades, otherwise the road grade can be neglected, as it only affects the estimated vehicle acceleration and drivetrain inertial contributions.

In case of states 1-4 (single gear), a backward calculation is adopted for deriving the input power of the active electric machine, through the drivetrain components efficiency maps (transmission and motor drive), and by taking into account the relevant inertial contributions deriving from the acceleration of the rotating parts of the system. Finally, the input power $P_{\text {input }}$ to the drivetrain can be calculated including or excluding the energy storage unit (e.g. the lithium-ion battery) efficiency properties. In this respect, the model described in (Gao, 2002) has been adopted. In case of states 5-8 (two gears engaged), characterised by the cooperative action of two electric motor drives, it is necessary to impose the air gap torque of one of the two electric motor drives (e.g. $T_{\text {mot,odd }}$ in Figure 10) and calculate the required torque of the other motor (e.g. $T_{m o t, e v e n}$ in Figure 10). For each wheel torque, vehicle speed and transmission state (and thermal condition in a second approximation analysis), this calculation has to be repeated for the possible range of torque distributions between the two electric motor drives, in order 
to select the most efficient condition between those giving origin to the same net transmission output torque. In case of significant absolute values of wheel torque or vehicle speed, some of the states or torque distributions will not be able to generate those conditions (i.e. an assigned $T_{m o t, o d d}$ will provoke a $T_{\text {mot,even }}$ exceeding the motor limits) and therefore will not be considered as viable alternatives for that specific operating condition.

Once the lowest input power to the electric drivetrain has been computed for each possible state, the most efficient state for that transmission output can be selected. For example, Table 3 plots the comparison of the electric motor/s input power between the different states for a wheel torque of 600 $\mathrm{Nm}$ and an assigned value of vehicle speed, for vehicle $\mathrm{A}$. The difference in power demand for the possible states fully justifies the adoption of this multiple-speed drivetrain.

Table 3 - Electric motor/s estimated input power comparison (in absolute value and percentage difference from the optimal state) for the different possible states of the dual-motor drivetrain, for a wheel torque of $600 \mathrm{Nm}$ and an assigned value of vehicle speed (vehicle A)

\begin{tabular}{lllllllll}
\hline & $\mathbf{1}$ & $\mathbf{2}$ & $\mathbf{3}$ & $\mathbf{4}$ & $\mathbf{5}$ & $\mathbf{6}$ & $\mathbf{7}$ & $\mathbf{8}$ \\
\hline Power [kW] & 39.94 & 38.39 & 39.99 & 40.18 & 39.40 & 38.59 & 38.79 & 40.24 \\
Percentage [\%] & 4.03 & 0.00 & 4.16 & 4.67 & 2.63 & 0.50 & 1.04 & 4.81 \\
\hline
\end{tabular}

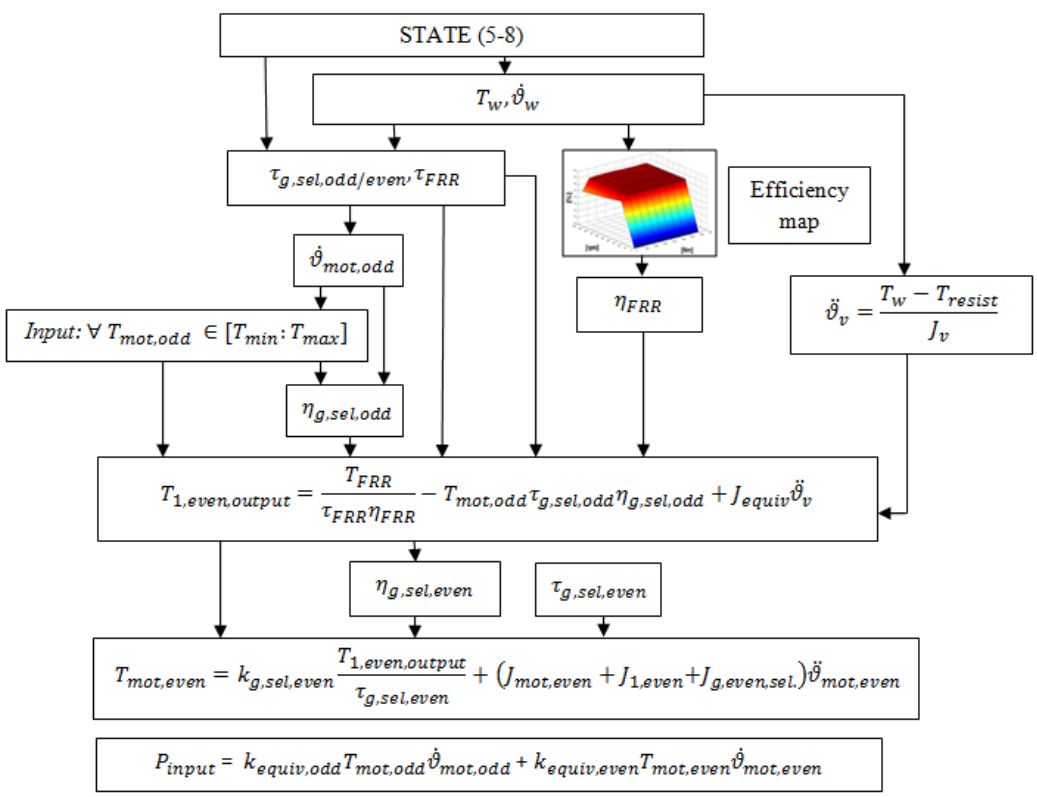

Figure 10 - Simplified flow chart of the procedure adopted for the computation of the input power to the electric powertrains for states 5-8, within the state and torque distribution optimisation procedure 
The whole procedure is repeated for the possible range of wheel torques, vehicle speeds and thermal conditions for each state, according to a 'brute force' algorithm, as the computational effort is still compatible with the capability of a personal computer. An optimisation run for the whole set of states, torques and speeds with reasonable parameter discretisation can be completed within 36 hours by a personal computer with 4 GB RAM and a dual-core $3 \mathrm{GHz}$ processor.

The output of the routine is constituted by two multi-dimensional look-up-tables: i) the look-up-table providing the most efficient drivetrain state for each wheel torque demand and vehicle speed (and, optionally, road grade and thermal condition); ii) the look-up-table providing the most efficient torque distribution for the two electric machines, as a function of the same input parameters as the look-up-table in i). The look-up-tables can be 'smoothed' using an interpolation function to improve the driveability and a logic system can be adopted to reduce the number of spurious state changes. The look-up-tables in i) and ii) can be used both in case of a backward facing simulator, in which the time history of wheel torque during a driving cycle is assigned, and in case of a forward facing simulator or an actual vehicle implementation, as the driver request in the transmission controller is expressed in the form of a wheel torque demand (Section 4). The state selection procedure implemented for this contribution does not consider the losses relating to tyre slip dynamics, however their inclusion is straightforward for more detailed studies.

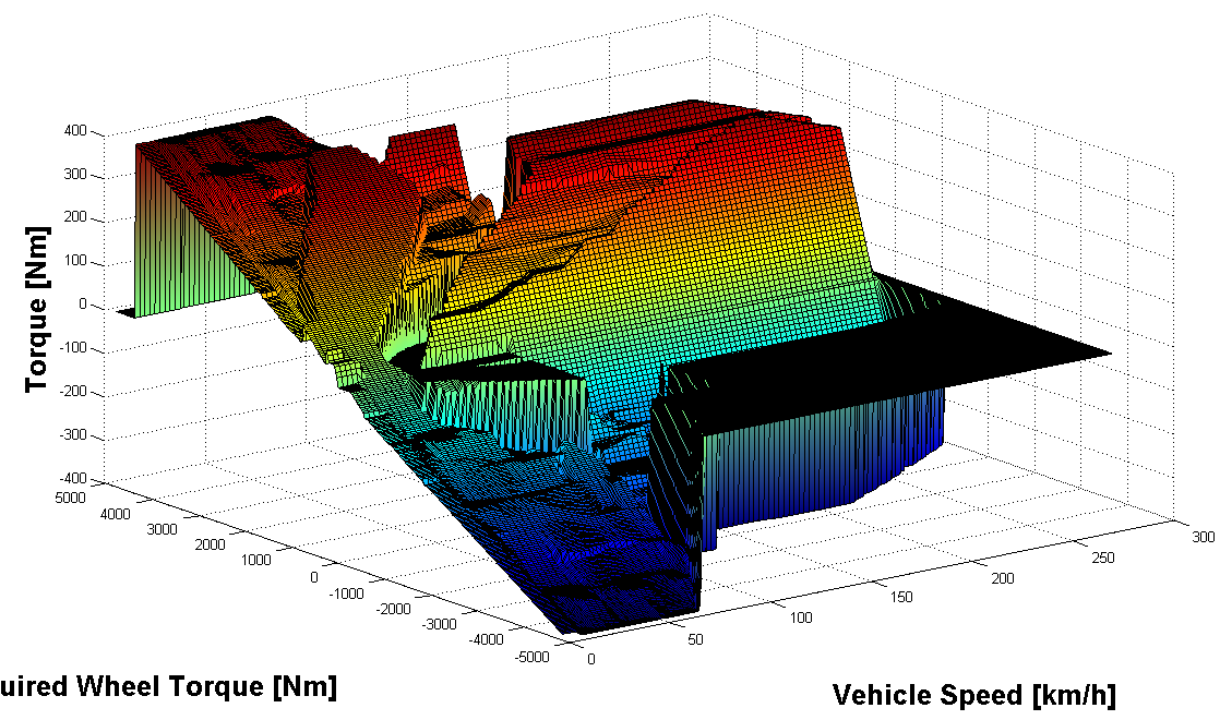

Figure 11 - Example of optimum 'even' motor torque as a function of the required wheel torque and vehicle speed

Figure 11 illustrates a typical map of the optimal values of 'even' motor torques as functions of the vehicle operating conditions. The authors have 
tested the optimisation procedure on several vehicle data sets in addition to case A and case B, and have noticed that the optimal states selected by the procedure often imply the adoption of a single-motor state in traction and a dual-motor state in regeneration. This is due to the fact that in a single-motor state the vehicle is characterised by a lower value of apparent mass than in conditions of dual-motor operation, and therefore requires less input power to accelerate, but provides less regenerative power. The confirmation of this statement derives from the application of the procedure to case study drivetrains with symmetrical efficiency maps of the electric motor drives. In fact, when the contribution of the inertial terms is neglected within the procedure, the ideal states and torque distributions are symmetrical in regeneration and traction.

The driving cycle simulation, even when adopting simplified backward facing models, needs to take into account the energy contribution relating to the gearshift dynamics, as the energy required for the second electric motor drive to be electrically synchronised with the transmission is supplied by the energy storage unit. This energy can be particularly relevant, for example in case of a gearshift between two single-gear states, as one of the motors will have to be accelerated from an initial standstill condition. This contribution is automatically taken into account in forward facing simulators, such as the one adopted for gearshift dynamics analysis in Section 4, whilst this aspect is usually neglected in backward facing simulators, which are the common simulation solution for gear ratio and state optimisation along driving cycles, because of their high computational efficiency. In a backward facing simulator, the energy balance $\Delta E_{\text {Gearshift }}$ during a gearshift can be approximated by:

$$
\begin{aligned}
\Delta E_{\text {Gearshift }}= & k_{\text {equiv,odd }}\left[\operatorname{flag}_{1, \text { odd }}\left(\frac{1}{2}\left(J_{\text {mot,odd }}+J_{1, \text { odd }}\right) \dot{\vartheta}_{v}^{2} \tau_{g, \text { odd,next }}{ }^{2} \tau_{F R R}{ }^{2}\right)\right. \\
& \left.- \text { flag }_{0, \text { odd }}\left(\frac{1}{2}\left(J_{\text {mot,odd }}+J_{1, \text { odd }}\right) \dot{\vartheta}_{v}^{2} \tau_{g, \text { odd,prev }}{ }^{2} \tau_{F R R}{ }^{2}\right)\right] \\
& +k_{\text {equiv,even }}\left[\text { flag }_{1, \text { even }}\left(\frac{1}{2}\left(J_{\text {mot,even }}+J_{1, \text { even }}\right) \dot{\vartheta}_{v}^{2} \tau_{g, \text { even,next }}{ }^{2}{\tau_{F R R}}^{2}\right)\right. \\
& - \text { flag } \\
&
\end{aligned}
$$

where $k_{\text {equiv,odd/even }}$ represents the equivalent efficiency (or the reverse of it) of the electric motor drive and (optionally) the energy storage unit during the manoeuvre. $\Delta E_{\text {Gearshift }}$ is added to the energy consumption estimation of the backward facing model along the driving schedule.

The conclusion is that the off-line methodology for the selection of the most energy efficient states described in this section provides optimal results when the vehicle is operated in a constant wheel torque and state condition, however the procedure gives origin to sub-optimal (but still indicative) 
results during a driving schedule. During a driving schedule, techniques such as dynamic programming and model predictive control can be used for the identification of the optimal sequence of states and a smooth transition (Beck, 2005).

\subsection{Results}

This paragraph deals with the comparison of the dynamic performance and energy consumption characteristics provided by single-speed single-motor drivetrains, double-speed single-motor drivetrains and four-speed dual-motor drivetrains installed in the case study vehicles A and B. Each of the main vehicle drivetrain parameters were optimised (from the viewpoint of energy efficiency) through backward facing simulations. In particular, the single-speed and double-speed vehicle drivetrains have been optimised according to the procedures described in (Sorniotti, 2010) and (Sorniotti, 2011).

Table 4a-Performance comparison for vehicles A and B

\begin{tabular}{|c|c|c|c|c|c|c|}
\hline $\begin{array}{l}\text { Case A - } \\
\text { Unladen }\end{array}$ & $\begin{array}{l}\text { Single- } \\
\text { Speed }\end{array}$ & $\begin{array}{l}\text { Double- } \\
\text { Speed }\end{array}$ & $\begin{array}{l}\text { Double } \\
\text { vs Single } \\
{[\%]}\end{array}$ & $\begin{array}{l}\text { Four - } \\
\text { Speed }\end{array}$ & $\begin{array}{l}\text { Four - } \\
\text { Speed vs } \\
\text { Single } \\
{[\%]}\end{array}$ & $\begin{array}{l}\text { Four - } \\
\text { Speed vs } \\
\text { Double } \\
{[\%]}\end{array}$ \\
\hline \multicolumn{7}{|c|}{ Case A } \\
\hline$V_{\max }[\mathrm{km} / \mathrm{h}]$ & 170 & 216 & 26.67 & 268 & 57.57 & 24.39 \\
\hline $0-10 \mathrm{~km} / \mathrm{h}[\mathrm{s}]$ & 0.72 & 0.43 & -40.28 & 0.42 & -41.67 & -2.33 \\
\hline $0-30 \mathrm{~km} / \mathrm{h}[\mathrm{s}]$ & 2.16 & 1.29 & -40.28 & 1.28 & -40.74 & -0.78 \\
\hline $0-60 \mathrm{~km} / \mathrm{h}[\mathrm{s}]$ & 4.35 & 2.60 & -40.23 & 2.57 & -40.92 & -1.15 \\
\hline $0-100 \mathrm{~km} / \mathrm{h}[\mathrm{s}]$ & 7.35 & 4.48 & -39.05 & 4.81 & -34.56 & 7.37 \\
\hline $70-120 \mathrm{~km} / \mathrm{h}[\mathrm{s}]$ & 3.82 & 3.45 & -9.69 & 3.45 & -9.69 & 0 \\
\hline \multicolumn{7}{|c|}{ Case B } \\
\hline$V_{\max }[\mathrm{km} / \mathrm{h}]$ & 165 & 165 & 0.01 & 166 & 0.69 & 0.68 \\
\hline $0-10 \mathrm{~km} / \mathrm{h}[\mathrm{s}]$ & 0.79 & 0.48 & -39.24 & 0.45 & -43.04 & -6.25 \\
\hline $0-30 \mathrm{~km} / \mathrm{h}[\mathrm{s}]$ & 2.39 & 1.45 & -39.33 & 1.37 & -42.68 & -5.52 \\
\hline $0-60 \mathrm{~km} / \mathrm{h}[\mathrm{s}]$ & 4.84 & 3.3 & -31.82 & 3.12 & -35.54 & -5.45 \\
\hline $0-100 \mathrm{~km} / \mathrm{h}[\mathrm{s}]$ & 9.11 & 8.26 & -9.33 & 7.47 & -18.00 & -9.56 \\
\hline $70-120 \mathrm{~km} / \mathrm{h}[\mathrm{s}]$ & 7.05 & 7.98 & 13.19 & 7.26 & 2.98 & -9.02 \\
\hline
\end{tabular}

Table $4 \mathrm{~b}$ - Energy consumption comparison for vehicles A and B

\begin{tabular}{llcl}
\hline & Single-Speed & Double-Speed & Four-Speed \\
\hline & \multicolumn{3}{c}{ Case A } \\
\hline NEDC $[\boldsymbol{k W h}]$ & 1.65 & 1.63 & 1.55 \\
FTP75 $[\boldsymbol{k W h}]$ & 2.59 & 2.57 & 2.49 \\
\hline & \multicolumn{3}{c}{ Case B } \\
\hline NEDC $[\boldsymbol{k W h}]$ & 1.08 & 1.02 & 0.98 \\
FTP75 $[\boldsymbol{k W h}]$ & 1.53 & 1.45 & 1.44 \\
\hline
\end{tabular}


The main results are reported in Tables $4 \mathrm{a}$ and $4 \mathrm{~b}$. The overall dynamic performance of the dual-motor four-speed system exceeds the dynamic performance of the other two more conventional drivetrain options. The single-speed drivetrain is incapable of providing acceptable dynamic performance, especially for vehicle A. Moreover, the energy consumption of the dual-motor drivetrain is consistently lower than the double-speed single-motor drivetrain, for a percentage between 3.2\% (FTP75, Federal Test Procedure 75) and 4.8\% (NEDC, New European Driving Cycle) for vehicle A, and a percentage between 3.8\% (NEDC) and 0.5\% (FTP75) for vehicle $\mathrm{B}$. The energy consumption values reported in the table have been obtained through a backward facing simulator and include the gearshift actuation energy contribution $\Delta E_{\text {Gearshift }}$ for the dual-motor drivetrain, whilst they neglect the same contribution (which has little relevance, as it can be deduced from Sorniotti, 2010) for the double-speed drivetrain.

\section{Conclusions}

The article presented a novel dual-motor clutchless drivetrain concept, which is being prototyped by the authors of this contribution belonging to industrial companies. A model of the seamless gearshift dynamics of the system has been presented. A methodology for the selection of the best operating states of the system for an assigned driving condition of the vehicle has been derived, and its practical limitations in terms of energy consumption optimisation along driving cycle simulations have been discussed. The performance and energy consumption characteristics of the novel drivetrain have been compared to those of a conventional single-speed drivetrain and a novel seamless double-speed drivetrain concept for two case study vehicles. The results demonstrate the significant benefit relating to the adoption of a multiple-speed transmission within an electric axle, and a further benefit, from marginal to significant depending on the driving cycle and vehicle application, through the adoption of the novel four-speed system. The energy consumption results of the dual-motor four-speed drivetrain are heavily influenced by the state selection and torque distribution algorithms, which will require further development and analysis, in conjunction with the optimisation of the gear ratios and motor size.

\section{References}

Renault. [online] Available at http://www.renault-ze.com/en-gb/renault-z.eelectric-vehicles-kangoo-fluence-zoe-twizy-1931.html, last accessed on $15^{\text {th }}$ February 2012. 
Ren, Q., Crolla, D.A., Morris, A., (2009) 'Effect of Transmission Design on Electric Vehicle (EV) Performance', IEEE Vehicle Power and Propulsion Conference, 7-10 September 2009, Dearborn, USA.

Sorniotti, A., Subramanyan, S., Turner, A., et al., (2011) 'Selection of the Optimal Gearbox Layout for an Electric Vehicle', SAE Int. J. Engines 4(1): 1267-1280, 2011.

Knodel, U., (2009) 'Electric Axle Drives for Axle-Split-Hybrids and EVApplications', $9^{\text {th }}$ European All-Wheel Drive Congress, 16-17 April 2009, Graz, Austria.

Rinderknecht, S., Meier, T., (2010) 'Electric Power Train Configurations and Their Transmission Systems', International Symposium on Power Electronics, Electrical Drives, Automation and Motion (SPEEDAM), Pisa, Italy, pp. $1564-1568$.

Rinderknecht, S., Meier, T., Fietzek, R., 'Electric Two-Drive-Transmission for E-Vehicles', VDI-Berichte, No. 2130, 2011.

Bologna, S., Fracchia, M., (2011) 'e-DCT: Compact Seamless Clutchless Transmission for Electric Vehicles', $10^{\text {th }}$ International CTI Symposium, 3-6 December 2011, Berlin, Germany.

Bologna, S., Everitt, M., Fracchia, M., Oerlikon Graziano S.p.A., Sistema di propulsione elettrico per veicoli, Italian Patent TO2011A000483, 2011.

Sorniotti, A., Holdstock, T., Loro Pilone, G., et al., (2012) 'Analysis and simulation of the gearshift methodology for a novel two-speed transmission system for electric powertrains with a central motor', Proceedings of the Institution of Mechanical Engineers, Part D: Journal of Automobile Engineering, Vol. 226, Issue 7, pp. 915-929, July 2012.

Holdstock, T., Sorniotti, A., Suryanto, et. al., (2012) 'Linear and Non-Linear Methods to Analyse the Drivability of a Through-the-Road Parallel Hybrid Electric Vehicle', Internation Journal of Powertrains, 2012 (accepted for publication).

Pacejka, H.B., (2006) 'Tire and Vehicle Dynamics', $2^{\text {nd }}$ Edition, SAE International. Warrendale, USA.

Nise, N.S., (2004) 'Control Systems Engineering', 4 ${ }^{\text {th }}$ Edition, John Wiley \& Sons, New York, USA.

Gao, L., Liu, S., Dougal, R.A., (2002) 'Dynamic lithium-ion battery model for system simulation', IEEE Transactions on Components and Packaging Technologies, Vol. 25, Issue 3, pp. 495 - 505.

Beck, R., Richert, F., Bollig., A., et al., (2005) 'Model Predictive Control of a Hybrid Vehicle Drivetrain', 44 ${ }^{\text {th }}$ IEEE Conference on Decision and Control, 2005 and 2005 European Control Conference, Seville, Spain, pp. 2670-2675.

Sorniotti, A., Boscolo, M., Turner, A., et al., (2010) 'Optimisation of a multi-speed electric axles as a function of the electric motor properties', IEEE Vehicle Power and Propulsion Conference, 1 - 3 September, 2010, Lille, France. 


\section{List of Symbols}

The subscript ' 0 ' is used to indicate an initial condition, the subscript 'prev' is used to indicate the previously selected gear and the subscript 'next' is used to indicate the next selected gear. A variable which is in the frequency domain is accented by a horizontal line.

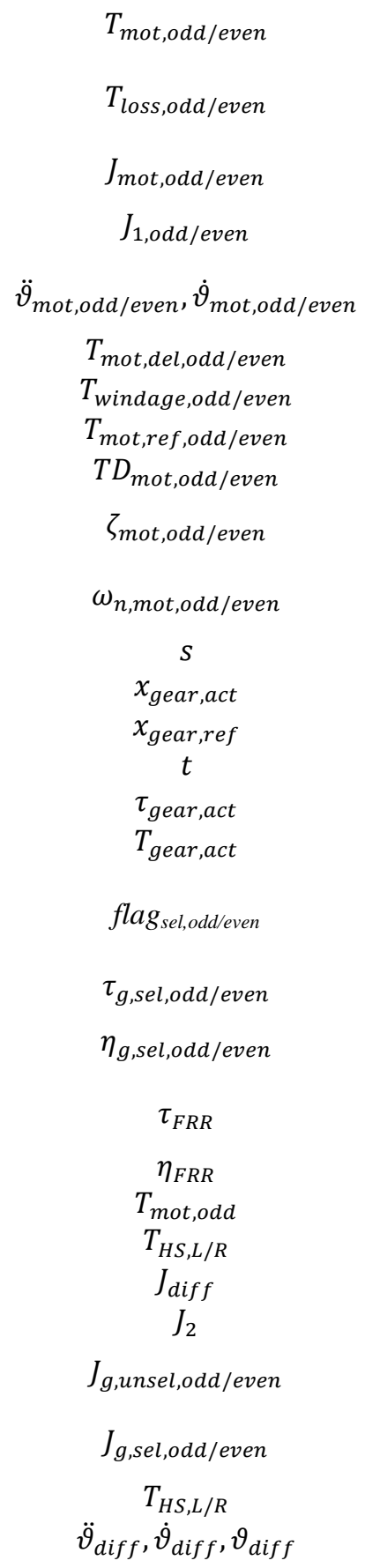

Torque of the 'odd'/'even' motor

Torque loss on the primary shaft of the 'odd'/'even' side of the drivetrain in conditions of both disengaged gears

Mass moment of inertia of the 'odd'/'even' motor Mass moment of inertia of the 'odd'/'even' primary shaft of the transmission

Angular acceleration and velocity of the 'odd'/'even' motor

Delayed air gap torque of the 'odd'/'even' motor

Windage torque of the 'odd'/'even' motor

Reference air gap torque of the 'odd'/'even' motor

Torque demand on the 'odd'/'even' motor

Damping ratio of the motor air gap torque characteristic

Natural frequency of the motor air gap torque characteristic

Laplace variable

Actual position of the gear actuator

Reference position of the gear actuator

Time

Time delay of the gear actuator

Time constant of the gear actuator

A Boolean variable (assuming 0 or 1 value) to select or deselect terms from the equation of motion of the system for the 'odd'/'even' side of the transmission Gear ratio selected on the 'odd'/'even' primary shaft Overall efficiency of the selected gear on the 'odd'/'even' primary shaft

Final reduction ratio (between the secondary shaft and the differential case)

Final reduction gear efficiency

Torque of the 'odd' electric motor

Left/right half-shaft torque

Mass moment of inertia of the differential

Mass moment of inertia of the secondary shaft

Mass moment of inertia of the unselected gear on the 'odd'/'even' primary shaft of the transmission Mass moment of inertia of the selected gear on the 'odd'/'even' primary shaft of the transmission Left/right half-shaft torque

Angular acceleration, velocity and displacement of 


$k_{H S, L / R}$
$c_{H S, L / R}$
$\Delta \dot{\vartheta}_{\text {diff-w,eq }}, \Delta \vartheta_{\text {diff-w,eq }}$
$\dot{\vartheta}_{w}, \vartheta_{w}$
$\Delta \vartheta_{\text {play }}$
$T_{T, \text { theor }}, F_{x, \text { theor }}$
$R_{W}$
$C_{s}$
$\dot{\vartheta}_{v}$
$\sigma$
$A_{x}, V$
$n_{\text {input }}$
$A_{x, i}$
$\varphi_{i}$
$u_{i}$
$T_{\text {ref,odd/even,EMS }}$
$T_{w, \text { ref }}$
$T D$

$T_{\text {ref,motor constant gear,roll-off comp }}$

$T_{w, \text { ref, motor gearshift }, E M S}$

$T_{w, \text { roll }-o f f}$

$T_{w, \text { ref, motor constant gear,EMS }}$

$\tau_{g, \text { mot constant gear }}$

$T_{\text {motor, theor }}$

$G_{P I D}$

$b_{m o t}$

$T_{\text {resist }}$

$J_{v}$

$T_{\min }$

$T_{\max }$

$T_{1, \text { even,output }}$ the differential

Left/right half-shaft torsion stiffness

Left/right half-shaft damping coefficient

Equivalent angular torsion speed and angle between the differential and the wheel

Angular velocity and displacement of the wheel

Half of the equivalent backlash (play) in the transmission, at the output port

Theoretical tyre torque and longitudinal force (without considering any dynamics)

Wheel radius

Tyre longitudinal slip stiffness

Equivalent angular speed of the vehicle

Slip ratio

Vehicle longitudinal acceleration, velocity

Number of inputs to the state space system

Vehicle longitudinal acceleration contribution due to the $\mathrm{i}^{\text {th }}$ input to the state space system

Phase angle of the vehicle longitudinal acceleration contribution due to the $i^{t h}$ input to the state space system

$i^{\text {th }}$ input to the state space system

Reference torque for the 'odd'/'even' electric motor calculated by the EMS

Reference wheel torque

Driver torque demand

Reference torque to the motor on the transmission side in conditions of constant gear during the roll-off phase of the upshift

Reference wheel torque contribution calculated by the EMS for the transmission side involved in the upshift

Estimated wheel torque for the transmission side involved in the upshift during the roll-off phase

Reference wheel torque calculated by the EMS for the transmission side in constant gear during the upshift

Gear ratio of the transmission side in condition of constant gear during the upshift

Theoretical motor torque

Transfer function of the Proportional Integral Derivative controller of the electric motor drive speed

Equivalent damping coefficient of the electric motor drive and transmission primary shaft in condition of both disengaged gears on the primary shaft

Resistive wheel torque, i.e. rolling resistance and aerodynamic torques

Equivalent mass moment of inertia of the vehicle Minimum electric motor torque at the current speed Maximum electric motor torque at the current speed Even primary shaft output torque 
Int. J. of Powertrains, Vol. $x$, No. $x, x x x x$

$T_{F R R}$
$k_{g, \text { sel,even }}$
$P_{\text {input }}$
$\Delta E_{\text {Gearshift }}$
$k_{\text {equiv,odd/even }}$

flag $_{0 / 1, \text { odd/even }}$
$T_{T, \text { del }}$
$m$
$g$
$a$
$b$
$L$
$C_{0 / 1 / 2, \text { front/rear }}$

$\tau_{\text {mot,odd/even }}$
$J_{\text {equiv. }}$
$J_{w}$
$L_{\text {tyre }}$
$a_{i, j}$
$b_{i, j}$
$X$
$U$
$A$

Differential output torque

Equivalent efficiency parameter of the 'even' gear Total input power required by the electric drivetrain Energy required during the gearshift to achieve the electric synchronisation Equivalent efficiency parameter of the 'odd'/'even' electric motor and optionally the energy storage system

Boolean variable equal to 0 or 1 depending on the state before and after the gearshift

Delayed tyre longitudinal torque

Mass of the vehicle

Gravity

Distance from the centre of gravity to the front axle

Distance from the centre of gravity to the rear axle

Wheel base

Rolling resistance coefficients (for the part independent from wheel speed, the part linearly dependent on wheel speed, and the part quadratically dependent on wheel speed)

Air density

Frontal area of the vehicle

Aerodynamic drag coefficient

Time constant of the 'odd'/'even' electric motor

Equivalent mass moment of inertia

Mass moment of inertia of the wheel

Tyre relaxation length

Element on the $i^{\text {th }}$ row and $j^{\text {th }}$ column of matrix A

Element on the $i^{\text {th }}$ row and $j^{\text {th }}$ column of matrix B

State vector

Input vector

State matrix

Input matrix 
9. Appendix A - List of the Main Vehicle Parameters

\begin{tabular}{|c|c|c|c|c|c|c|}
\hline & Case A & & & Case B & & \\
\hline & $\begin{array}{l}\text { Single- } \\
\text { Speed }\end{array}$ & $\begin{array}{l}\text { Double- } \\
\text { Speed }\end{array}$ & $\begin{array}{l}\text { Four- } \\
\text { Speed }\end{array}$ & $\begin{array}{l}\text { Single- } \\
\text { Speed }\end{array}$ & $\begin{array}{l}\text { Double- } \\
\text { Speed }\end{array}$ & $\begin{array}{l}\text { Four- } \\
\text { Speed }\end{array}$ \\
\hline Differential ratio [-] & 2.24 & 2.24 & 2.24 & 2.24 & 2.24 & 2.24 \\
\hline $1^{\text {st }}$ Gear ratio [-] & 1.615 & 3.75 & 3.19 & 2.25 & 5.25 & 4.5 \\
\hline $2^{\text {nd }}$ Gear ratio [-] & - & 1.275 & 2.23 & - & 1.3125 & 4 \\
\hline $3^{\text {rd }}$ Gear ratio [-] & - & - & 1.03 & - & - & 2.5 \\
\hline $4^{\text {th }}$ Gear ratio [-] & - & - & 1 & - & - & 1.25 \\
\hline $\begin{array}{l}\text { Max motor power } \\
{[\mathrm{kW}]}\end{array}$ & 335 & 335 & 167.5 & 50 & 50 & 25 \\
\hline $\begin{array}{l}\text { Max motor torque } \\
{[\mathrm{Nm}]}\end{array}$ & 800 & 800 & 400 & 160 & 160 & 80 \\
\hline $\begin{array}{l}\text { Max motor speed } \\
{[\mathrm{rpm}]}\end{array}$ & 5,000 & 5,000 & 5,000 & 14,000 & 14,000 & 14,000 \\
\hline $\begin{array}{l}\text { Motor mass moment } \\
\text { of inertia }\left[\mathrm{kgm}^{2}\right]\end{array}$ & 0.18 & 0.18 & 0.108 & 0.094 & 0.094 & 0.054 \\
\hline Mass $[\mathrm{kg}]$ & 2109 & & & 650 & & \\
\hline Wheelbase [m] & 2.6 & & & 2 & & \\
\hline $\begin{array}{l}\text { Height of centre of } \\
\text { gravity }[\mathrm{m}]\end{array}$ & 0.5 & & & 0.48 & & \\
\hline $\begin{array}{l}\text { Aerodynamic drag } \\
\text { coefficient [-] }\end{array}$ & 0.28 & & & 0.32 & & \\
\hline $\begin{array}{l}\text { Frontal area of the } \\
\text { vehicle }\left[\mathrm{m}^{2}\right]\end{array}$ & 2.6 & & & 2.2 & & \\
\hline Wheel radius [m] & 0.327 & & & 0.31 & & \\
\hline
\end{tabular}

\section{Appendix B - Example of State-Space Equations of the System}

State vector

$$
X=\left[\begin{array}{c}
T_{\text {mot,del,odd }} \\
T_{\text {mot,del,even }} \\
\vartheta_{\text {diff }} \\
\dot{\vartheta}_{\text {diff }} \\
\vartheta_{w} \\
\dot{\vartheta}_{w} \\
\dot{\vartheta}_{v} \\
T_{T, \text { del }}
\end{array}\right]
$$

Input vector 
Int. J. of Powertrains, Vol. $x$, No. $x, x x x x$

$$
U=\left[\begin{array}{c}
T_{\text {mot,theor }, \text { odd }} \\
T_{\text {mot,theor, even }} \\
\frac{R_{w} m g a}{L}\left(C_{0, \text { rear }}-C_{2, \text { rear }} R_{w}^{2} \dot{\vartheta}_{v, 0}^{2}\right) \\
\frac{R_{w} m g b}{L}\left(C_{0, \text { front }}-C_{2, \text { front }} R_{w}^{2} \dot{\vartheta}_{v, 0}^{2}\right) \\
\frac{1}{2} \rho S C_{d} R_{w}^{3} \dot{\vartheta}_{v, 0}^{2} \\
2 F_{x, 0}
\end{array}\right]
$$

\section{State matrix}

$$
A=\left[\begin{array}{cccccccc}
a_{1,1} & 0 & 0 & 0 & 0 & 0 & 0 & 0 \\
0 & a_{2,2} & 0 & 0 & 0 & 0 & 0 & 0 \\
0 & 0 & 0 & a_{3,4} & 0 & 0 & 0 & 0 \\
a_{4,1} & a_{4,2} & a_{4,3} & a_{4,4} & a_{4,5} & a_{4,6} & 0 & 0 \\
0 & 0 & 0 & 0 & 0 & a_{5,6} & 0 & 0 \\
0 & 0 & a_{6,3} & a_{6,4} & a_{6,5} & a_{6,6} & 0 & a_{6,8} \\
0 & 0 & 0 & 0 & 0 & 0 & a_{7,7} & a_{7,8} \\
0 & 0 & 0 & 0 & 0 & a_{8,6} & a_{8,7} & a_{8,8}
\end{array}\right]
$$

where:

$$
\begin{aligned}
& a_{1,1}=-\frac{1}{\tau_{\text {mot,odd }}} \quad a_{2,2}=-\frac{1}{\tau_{\text {mot,even }}} \quad a_{3,4}=1 \\
& a_{4,1}=\frac{\tau_{g, \text { sel,odd }} \eta_{\text {g,sel,odd }} \tau_{F R R} \eta_{F R R}}{J_{\text {equiv. }}} \quad a_{4,2}=\frac{\tau_{g, \text { sel,even }} \eta_{g, \text { sel,even }} \tau_{F R R} \eta_{F R R}}{J_{\text {equiv. }}} \\
& a_{4,3}=-\frac{K_{H S}}{J_{\text {equiv. }}} \quad a_{4,4}=-\frac{c_{H S}}{J_{\text {equiv. }}} \quad a_{4,5}=\frac{K_{H S}}{J_{\text {equiv. }}} \quad a_{4,6}=\frac{c_{H S}}{J_{\text {equiv. }}} \\
& a_{5,6}=1 \quad a_{6,3}=\frac{K_{H S}}{2 J_{w}} \quad a_{6,4}=\frac{c_{H S}}{2 J_{w}} \quad a_{6,5}=-\frac{K_{H S}}{2 J_{w}} \\
& a_{6,6}=-\frac{c_{H S}}{2 J_{w}}-\frac{\frac{R_{w}^{2} m g a}{L}\left(C_{1, \text { rear }}+C_{2, \text { rear }} R_{w} \dot{\vartheta}_{v, 0}^{2}\right)}{2 J_{w}} \quad a_{6,8}=-\frac{1}{2 J_{w}} \\
& a_{7,7}=-\frac{\rho S C_{d} R_{w}^{3} \dot{\vartheta}_{v, 0}}{2 J_{w}+m R_{w}^{2}}-\frac{\frac{R_{w}^{2} m g b}{L}\left(C_{1, \text { front }}+C_{2, \text { front }} R_{w} \dot{\vartheta}_{v, 0}^{2}\right)}{2 J_{w}+m R_{w}^{2}} \quad a_{7,8}=\frac{1}{2 J_{w}+m R_{w}^{2}} \\
& a_{8,6}=\frac{2 C_{s} R_{w} \dot{\vartheta}_{v, 0} / \dot{\vartheta}_{w, 0}{ }}{L_{\text {tyre }} /\left(\dot{\vartheta}_{v, 0} R_{w}\right)} \quad a_{8,7}=-\frac{2 C_{s} R_{w} / \dot{\vartheta}_{w, 0}}{L_{\text {tyre }} /\left(\dot{\vartheta}_{v, 0} R_{w}\right)} \quad a_{8,8}=-\frac{1}{L_{\text {tyre }} /\left(\dot{\vartheta}_{v, 0} R_{w}\right)}
\end{aligned}
$$

Input matrix 
Int. J. of Powertrains, Vol. $x$, No. $x, x x x x$

$$
B=\left[\begin{array}{cccccc}
b_{1,1} & 0 & 0 & 0 & 0 & 0 \\
0 & b_{2,2} & 0 & 0 & 0 & 0 \\
0 & 0 & 0 & 0 & 0 & 0 \\
0 & 0 & 0 & 0 & 0 & 0 \\
0 & 0 & 0 & 0 & 0 & 0 \\
0 & 0 & b_{6,3} & 0 & 0 & 0 \\
0 & 0 & 0 & b_{7,4} & b_{7,5} & 0 \\
0 & 0 & 0 & 0 & 0 & b_{8,5}
\end{array}\right]
$$

where:

$$
\begin{array}{lcc}
b_{1,1}=\frac{1}{\tau_{\text {motor }, \text { odd }}} & b_{2,2}=\frac{1}{\tau_{\text {motor, even }}} & b_{6,3}=-\frac{1}{2 J_{w}} \\
b_{7,4}=-\frac{1}{2 J_{w}+m R_{w}^{2}} & b_{7,5}=\frac{1}{2 J_{w}+m R_{w}^{2}} & b_{8,6}=\frac{R_{w}}{L_{\text {tyre }} /\left(\dot{\vartheta}_{v, 0} R_{w}\right)}
\end{array}
$$

